\title{
Mahalli İdarelerce Yürütülen Hizmetlere İlişkin Şikâyetlerin İncelenmesi ve Yerel Yönetimler Kamu Denetçisinin Gerekliliği
}

\section{Examination of Complaints Regarding Services Provided by Local Administrations and Necessity of Local Government Ombudsman}

\section{Dr. Öğr. Üyesi Kürşad Emrah Yıldırım ${ }^{1}$}

Başvuru Tarihi: 16.09.2019

Kabul Tarihi: 30.09.2019

\section{Öz}

Kamu denetçiliği, kurumsal olarak ilk kez İsveç’te uygulanmaya başlanmıştır. Kamusal nitelikteki hizmetlerin sunumu sırasında bir takım bürokratik eylemlerin bulunması, onların denetlenmesini ve bu denetimi yerine getirecek kamu denetçiliği kurumu gibi bir yapıyı gerekli kıldığı düşünülmektedir. Bağımsız olma ve tarafsılılk ilkeleri doğrultusunda vatandaşları idarenin keyfi uygulamalarına karşı güvende hissetmelerine yönelik hareket edebilmeleri için zamanla birçok ülkede varlık göstermeye başlamıştır. Kamu denetçiliği kurumu, zamanla birçok ülkeye yayılmıştır. Türkiye'de de 2012 yılı 6328 sayılı "Kamu Denetçiliği Kurumu Kanunu” ile Kamu Denetçiliği Kurumu kurulmuş ve 1982 Anayasası'nın 74. maddesiyle anayasal bir kurum haline getirilmiştir. Kamu Denetçiliği Kurumu, idarenin işleyişi ve her türlü eylem, işlem, tutum ve davranışını gelen şikâyetler üzerine incelemekle görevli olan ve bu incelemeler sonucunda idareye öneriler sunan bir kurumdur. Kamu Denetçiliği Kurumu'nun yıllik faaliyet raporları incelendiğinde mahalli idareler ile ilgili şikâyetlerin diğer şikâyetlerden ayrı olarak sinıflandırlldı̆g görülmektedir. Bununla birlikte bu kuruma gelen ve incelemeye konu olan şikâyetlerin önemli bir kısmını mahalli idareler oluşturmaktadır. Çalışmada söz konusu raporlarda yer alan ve "Mahalli İdarelerce Yürütülen Hizmetlere İlişkin Şikayetler" tablolaştırılarak incelenmiş ve yapılan incelemeden elde edilen sonuçlar üzerinden yerel kamu denetçisinin gerekliliği üzerinde durulmuştur.

Anahtar Kelimeler: Mahalli İdareler, Kamu Denetçiliği Kurumu, Ombudsman, Yerel Kamu Denetçisi

\footnotetext{
${ }^{1}$ Anadolu Üniversitesi, İIBF, keyildirim@anadolu.edu.tr, ORCID: 0000-0002-7824-4916
} 


\section{Abstract}

Ombudsman, expressed as Public supervisorship, in the first time it has been implemented in Sweden. It is believed that during the presentation of public services, some bureaucratic actions, they are supervised and they require a structure such as ombudsman institution which will carry out this inspection. The Ombudsman Institution has begun to appear in many countries over time in order to enable its citizens to feel safe against the arbitrary practices of the administration in line with the principles of independence and impartiality. In the Turkey with number of 6328 "Ombudsman Act" the Ombudsman was established years of 2012 and has been turned into a constitutional institution with Article 74 of the 1982 Constitution. The Ombudsman's Institution is an institution that is responsible for examining the operation of the administration and all its actions, actions, attitudes and behaviors on complaints and offers recommendations to the administration as a result of these investigations. When the activity reports of the Ombudsman's Institution are examined, it is seen that the complaints about the local administrations are classified separately from other complaints. Therewithal, local administrations constitute a significant part of the complaints received from this institution. In this study, the complaints, which are included in the said reports and concluded with respect to Local Administrations, were tabulated and the necessity of local ombudsman was discussed through the results obtained from the examination.

Keywords: Local Administrations, Ombudsman Institution, Ombudsman, Local Ombudsman

\section{Giriş}

Çeşitli şikâyet ve isteklerden hareket ile şikâyetlere sebep olan olayın tarafları arasında arabuluculuk yapan, çözüm önerileri sunan ve dilimizde kamu denetçiliği olarak karşılık bulan kavramın tarihsel gelişimi incelendiğinde, temellerinin Osmanlı Devleti'nde mevcut bazı yapılarda yer aldığı görülmektedir. Kökenleri tarihimize dayanan kamu denetçiliğinin ülkemizde uygulanmaya 2012 yılında yürürlüğe giren 6328 nolu kanun ile başlandığı bilinmektedir.

İdarenin çeşitli eylem ve işlemlerinden dolayı vatandaşların bazen haksız uygulamalar ile karşı karşıya kaldığı bir gerçektir. Haksız uygulamalar karşısında vatandaşların taleplerini inceleyen ve çözüm önerileri getiren kamu denetçiliği kurumu, bu uygulamaların önlenmesinde kolay ulaşılabilir ve bürokratik zaman kaybının az olduğu önemli bir denetim mekanizmasıdır.

Özellikle Avrupa ülkelerinde çok çeşitli uygulamaları olan kamu denetçiliğinin ülkemizde çeşitlilik açısından daha kısır bir görüntü sergilediğini söylemek mümkündür. Örneğin diğer ülke uygulamalarına bakıldığında kamu denetçiliğinin; vergi, sağlık, tüketici, askeri, yerel yönetim, banka kamu denetçiliği gibi sınıflandırıldığı ve daha alt uzmanlık alanlarına ayrıldığı görülmektedir. Ülkemizdeki uygulamada ise idare ile ilgili tüm konular ile ilgilenen tek bir yapının var olduğu ve değerlendirmelerin konu tasnifi yapılarak her tasnif için ayrı denetçilerin belirlenmesi usulü ile gerçekleştirildiği görülmektedir. Kamu denetçiliği kurumunun gerçekleştirdiği faaliyetleri gösteren raporlar incelendiğinde bu konular içerisinde önemli 
sayılabilecek bir çoğunluğun yerel yönetimler ile ilgili kararlara ait olduğu gözlemlenmektedir. Çalışmada bu raporlardaki yerel yönetim kararları incelenerek yerel yönetim kamu denetçiliğinin ülkemizdeki gerekliliği üzerine bir değerlendirme yapılmaya çalışılmıştır.

\section{Kamu Denetçiliği}

Kamu denetçiliği ile ilgili kaynaklar incelendiğinde kavramın İsveç kökenli olduğu görülmektedir. Daha detaylı bir inceleme ile kavramın ilk uygulamasının Osmanlı Devleti'nde olduğu ve İsveç Kralı Şarl'ın 18.yy'da Osmanlıya konuk olduğu dönemlerde görüp ülkesinde uyguladığı ortaya çıkmaktadır (Uler, 2012, s. 500). Eski Türk-İslam devletlerinde Divan-1 Mezalim, Osmanlı Devleti döneminde ise Divan-ı Hümayun olarak karşımıza çıkan meclislerin görevleri arasında vatandaşın şikâyetlerinin dinlenmesi ve bunların padişahlık makamı adına çözüme kavuşturulması yer almaktaydı (Avşar, 2012, s. 31). Bu durum o dönemlerde vatandaş ile yönetim arasındaki yakın ilişkiyi de ortaya koymaktadır. Hatta şikayetlerin dinlenmesi ve çözüme kavuşturulması için gerekli çabanın gösterilmesi denetim mekanizmasının işlerliğini de göstermektedir.

Kamu yönetiminde denetim mekanizması, kamu yöneticilerinin görevlerini icra ederken sahip oldukları yetkileri kötüye kullanmalarının önüne geçmek için gereklidir. Bir diğer neden olarak kanunlarının bu yöneticilere yapmak üzere verdiği görevlerin amaçlara uygun olarak yerine getirilip getirilmediğinin tespit edilebilmesidir (Tortop vd., 1993, s. 157). Kamu yönetiminde denetim siyasal, yönetsel, yargısal denetimin yanı sıra baskı grupları ve kamuoyu denetimi, etik denetimi ve kamu denetçiliği aracılığı ile yapılmaktadır (Özer ve Önen, 2012, s. 251-253). Kamu yönetimi tarafından icra edilen faaliyetler ile ilgili şikâyetleri çözmek ve aşırılıkları gidermek ile sorumlu olan kamu denetçiliği, yargı organlarının denetim yaparken göz ardı ettiği yerindelik denetimini gerçekleştirmektedir (Şengül, 2013, s. 86). Yerindelik denetimi, kamu örgütlerine sorunları çözmek için daha hızlı bir geri dönüş sağlamaktadır.

Vatandaşın kamu yönetimi ile ilgili şikâyetlerini belirleyerek aksayan ve kusurlu durumları düzeltmek amacı ile ulaştı̆̆ı sonuçları kamuoyuna ve meclise sunan (Eryılmaz, 2011, s. 343) kamu denetçiliği kurumunun aldığı kararların bir bağlayıcılığı olmayıp (Nohutçu, 2007, s. 300) bu kararlar tavsiye niteliğindedir.

Kamu denetçiliği gibi hassas bir kurumun aldığı kararların, fayda sağlayan bir değer taşıyabilmesi için bu kurumun yürütmeden bağımsız olması gerekmektedir. Nitekim kamu denetçisi, yönetimi denetleme aşamasında yönetime yabancı değildir ancak yönetime bağlı da hareket etmemektedir (Uler, 2012, s. 503). Diğer bir ifadeyle vatandaşların kamu kurum ve kuruluşları ile olan münasebeti dolayısıyla yaşadıkları sorunlar ile dile getirmek istedikleri şikayetlerine gerektiği gibi önem vererek çözüm bulmak ve gerektiğinde arabulucuk yapmak gibi amaçları taşıyan kamu denetçiliği kurumu, bağımsız olma ve tarafsızlık ilkeleri doğrultusunda hareket etmesi gerekmektedir (Gökçe, 2013, s. 4). Bununla birlikte vatandaşlar tarafından gelen şikâyetleri değerlendirmesi, değerlendirme yapılırken kötü işleyiş ve haksızlık içeren konuların önüne geçilmesi veya ortaya çımış olan sonuçlara önlem niteliğinde öneriler sunması (Tortop, 1998, s. 4), kamu denetçisinin yapması gereken görevler arasında sayılmaktadır. 
Kamu denetçiliği uygulamaları incelendiğinde bu denetim mekanizmasının üçlü bir sınıflandırmaya tabi olduğu görülmektedir. Bu sınıflandırmalar içerisinde farklı türler yer almaktadır. Kamu denetçiliği uygulamalarından ilki "klasik kamu denetçiliği" olarak isimlendirilen ve en yaygın kullanılan denetçiliktir. Klasik kamu denetçiliği kamu kurumları ile vatandaşlar arasındaki kusurların giderilmesi ile ilgilenmektedir. Bir diğer kamu denetçiliği "avukat kamu denetçiliği” dir. Bu denetçilik türünde taraflar içerisinde kamu kurumlarının olma zorunluluğu yoktur. Her iki tarafın vatandaş olması ve aralarından bir uyuşmazlığın olması durumunda faaliyet göstermektedir. Üçüncü denetçilik çeşidi olan "kurumsal kamu denetçiliği” ise özel kurumlar ile vatandaşlar arasındaki veya özel kurumun kendi içindeki uyuşmazlıkların çözümü ile ilgilenmektedir (Özden, 2010, s. 50-52). Bu sinıflandırma içerisinde yer alan bazı denetçilik türlerini şu şekilde sıralamak mümkündür:

- Parlamento Kamu Denetçiliği

- İnsan Hakları Kamu Denetçiliği

- Çocuk Hakları Kamu Denetçiliği

- Askeri Kamu Denetçiliği

- Banka Kamu Denetçiliği

- Tüketici Kamu Denetçiliği

- Basın Kamu Denetçiliği

- Vergi Kamu Denetçiliği

- Sağlık Kamu Denetçiliği

- Fırsat Eşitliği Kamu Denetçiliği

- Özel Sektör Kamu Denetçiliği

- Öğrenci ve Eğitim Kamu Denetçiliği

- Uluslararası ve Uluslar üstü Kamu Denetçiliği

- Yerel Yönetimler Kamu Denetçiliği

Türkiye'de 1970'li yıllardan başlayarak tartışma konusu olan ve 2010 yılında yapılan Anayasa değişikliği ile kuruluşu kesinleşen, (Odyakmaz, 2011, s. 106) kamu denetçiliği, 2012 yılında 6328 sayılı "Kamu Denetçiliği Kurumu Kanunu” ile faaliyetlerine başlamıştır. İlgili kanunun 1. maddesinde kurumun; "kamu hizmetlerinin işleyişinde bă̆ımsız ve etkin bir şikâyet mekanizması oluşturmak suretiyle, idarenin her türlü eylem ve işlemleri ile tutum ve davranışlarını; insan haklarına dayalı adalet anlayışı içinde, hukuka ve hakkaniyete uygunluk yönlerinden incelemek, araştırmak ve önerilerde bulunmak” üzere kurulduğu görülmektedir. Yine aynı kanunun 5. maddesinde kurumun görevi; "idarenin işleyişi ile ilgili şikâyet üzerine, idarenin her türlü eylem ve işlemleri ile tutum ve davranışlarını; insan haklarına dayalı adalet anlayışı içinde, hukuka ve hakkaniyete uygunluk yönlerinden incelemek, araştırmak ve idareye önerilerde bulunmak” şeklinde tanımlanmıştır. Diğer ülke örneklerinde görülen çeşitliliğin aksine Türkiye'de herhangi bir çeşitlendirme yapılmadan tüm başvurular tek bir kamu denetçiliği merciinde toplanmakta ve değerlendirilmektedir.

Farklı ülkelerde göreve gelme usulleri ve yetki alanları farklılık göstermesine rağmen temel amacı kamu idaresi karşısında vatandaşlara ait hakların korunması ve kamusal sorunların çözümünün hızlandırılması olan kamu denetçileri özellikle yargının yükünün azaltılmasında önemli bir role sahiptir. Amerika, Kanada, Almanya, İsveç, Macaristan gibi birçok ülkede farklı 
alanlara ayrılmış olan kamu denetçiliği, Türkiye, Fransa, Danimarka, Polonya gibi ülkelerde çeşitlilik göstermeden tek bir alanda uygulanmaktadır (Özden, 2010, s. 70-71). Kamu denetçiliğinin temel görevi adalet, hakkaniyet ve hukuk çerçevesinde idare adına gelen şikayetler üzerine incelemeler yapmak ve şikayetlerin giderilmesi için çözümler sunmaktır (Parlak ve Doğan, 2015, s. 757-758).

\section{Yerel Yönetimler Kamu Denetçiliği}

Klasik kamu denetçiliği sınıflandırması içerisinde yer alan ve kamu denetçiliği ile ilgili ülke örnekleri incelendiğinde en yaygın kullanıma sahip olan yerel yönetimler kamu denetçiliğinin ilk uygulaması 1974 yılında İngiltere'de başlatılmıştır. Zamanla yerel yönetimlerin yerine getirmeleri gereken görevlerin değişikliğe uğraması ve giderek artması gibi nedenlerle merkezi yönetim organları için kurulan kamu denetçilerinin yanında yerel yönetim kamu denetçilerinin oluşturulması da yaygınlaşmıştır (Sanal, 2002, s. 62). Yerel yönetimlerin gerektiği gibi yönetilmemesi ve faaliyetler sonucu sorunların ortaya çıması ve bu sorunların çözülüp yerel yönetimlerin gerektiği gibi yönetilmesi amacıyla görev yapmaya başlamıştır (Küçüközyiğit, 2006, s. 95). Çeşitli ülkelerde daha etkin ve verimli bir yerel yönetim sisteminin sağlanması ve yaşanan aksaklıkların tespit edilerek giderilmesi için yerel denetim mekanizmasının oluşturulması gerekli görülmüştür.

Yerel yönetimler kamu denetçiliği, belirli bir bölgede veya şehirde faaliyet gösteren yerel yönetim birimlerinin işleyişi sonucu ortaya çıkan sorunların çözüme kavuşturulabilmesi, yerel halkın haklarının yerel yönetimlere karşı korunabilmesi ve yerel yönetimlerin yönetsel anlamda daha sağlıklı hale gelmesi amacıyla öneriler sunmak üzere kurulmuş kamu denetçiliğidir (Ataman, 1997, s. 783). Bu denetçilik türü müdahale alanı ölçüsünde etki ve otoritesi sınırlandırılmış olan ve merkezi yönetimin bütün özelliklerini taşıyan kamu denetçiliğidir (Temizel, 1997, s. 65). Hizmette yerellik, yerel özerklik, katılım, küreselleşme gibi kavramlarda yaşanan gelişmeler ile birlikte dünya genelinde yerel yönetimlere daha fazla sorumluluk ve yetki verilmeye başlanmıştır (Özden, 2004, s. 564). Yerel yönetimlerin artan önemi ile birlikte yerel yönetim kamu denetçiliği de buna paralel olarak uygulandığı ülke sayısı bakımından artış göstermektedir.

Bir kamu deneticisinin uluslararası tanımı karşılayabilmesi ve kabul görebilmesi için denetçilik görevini kendisine veren makam veya şahısları da kapsayacak şekilde tüm makam ve şahıslar karşısında bağımsız ve tarafsız olması gerekmektedir (Gregory, 1995, s. 12). Dolayısıyla yerel yönetimler kamu denetçisinin de bu ölçütü sağlaması önemli bir zorunluluktur.

Küresel uygulamaları incelendiğinde, yerel yönetimler kamu denetçisi, parlamento kamu denetçisi gibi parlamento tarafından belirlenmekte ve görevlendirilmektedir. Bazı ülkeler ise yerel yönetimler kamu denetçisi belirlemede yerel meclislerin de katılımı ile gerçekleştirdikleri oylama yöntemini kullanmaktadırlar (Ünal, 2008, s. 133). Diğer kamu denetçileri gibi geniş yetkileri olan ve yargı kuruluşlarında var olan yetkilere benzer yetkileri elinde bulunduran (Akıncı, 1999, s. 344) yerel yönetimler kamu denetçileri, yaptıkları denetimler sonucunda disiplin soruşturmasına veya yargıya başvurma, anayasaya aykırılık bildirimi yapma, kanun veya düzenlemeler ile ilgili reform tekliflerinde bulunma gibi haklara da sahiptirler (Köksal, 2007, s. 51). Yerel yönetimler kamu denetçilerine, denetçinin yetki alanı içerisinde yer alan 
kurum ve kuruluşların faaliyetlerinden zarar görmüş olan tüm vatandaşlar, tüzel kişiler ve ülkede yaşayan yabancılar şikâyet başvurusu yapabilmektedir (Seneviratne, 1994, s. 102). Yapılan başvurular değerlendirilirken, yerel meclisler tarafından alınan kararlara ait uygulamaların gerektiği gibi yapılıp yapılmadığından çok bu uygulamalara kalite kazandırılabilir olup olmadığı ve hukuk ilkelerine uygun olarak yapılıp yapılmadığı dikkate alınmaktadır (Temizel, 1997s. 66). Bir başvurunun değerlendirmeye alınabilmesi için başvuruda bulunacak kişinin adli ve idari denetim araçlarının hepsine başvurmuş ve bunları tüketmiş olması gerekir. Aksinin tespiti durumunda yerel yönetimler kamu denetçisi başvuru yapacak kişinin şikâyetini kabul etmeyecektir (Özden, 2010, s. 69).

Ülke örnekleri incelendiğinde kamu denetçilerinin göreve getirilmelerinde farklı yöntemlerin olduğu görülmektedir. Örneğin Amerika Birleşik Devletleri’nde yerel düzeyde ve farklı faaliyet alanları ile ilgili çeşitlli kamu denetçilerinin var olduğu ve yerel düzeyine göre o bölgedeki yerel yöneticiler tarafından atandığı̆ görülmektedir. Benzer şekilde Kanada'da yerel meclisin teklifi ile yerel yöneticiler tarafından atama yapıldığı görülmektedir. Hollanda gibi bazı ülkelerde yerel kamu denetçileri yerel meclislerce seçilmektedir. İspanya'da yerel kamu denetçilerinin yanı sıra bölgesel düzeyde kamu denetçileri mevcuttur. Bu denetçilerin tamamı ulusal kamu denetçisi gibi parlamento tarafından seçilmektedir (Şencan, 2011, s. 9-39). Kamu denetçiliğinde önemli olan her ülkenin kendisine ait sosyal, politik, hukuksal, kültürel ve nüfus özelliklerine göre bir kurumsal yapının oluşmasıdır. Dolayısıyla kamu denetçiliğinde ülkeye sağılılı işleyen bir sistem kurulmak isteniyorsa başka ülkelerden kopya etmekten ziyade o ülkenin koşullarına göre tasarlanan bir kurum oluşturulmalıdır (Fendoğlu, 2010, s. 19). Ülkelerin temel dinamiklerinin, yerel yönetimler yapısının ve merkezi ve yerel yönetimler arası ilişkilerin yerel kamu denetçiliği kurumunun oluşturulmasına olanak tanıması gerekmektedir.

\section{Kamu Denetçiliği Raporlarinda Mahalli İdarelerce Yürütülen Hizmetlere Ilişkin Şikayetler}

Kamu denetçiliği mahalli idareler ile ilgili faaliyetlerine, 6328 sayılı kanunun öngörüsü üzerine 29/03/2013 tarihinde başlamıştır. Kamu Denetçiliği Kurumu'nun internet sayfasından alınan faaliyet raporları incelendiğinde 2013 yılından itibaren raporların hazırlandığı ve en son 2018 yilı raporunun sistemde var olduğu görülmektedir. Söz konusu raporlar incelendiğinde Kamu Denetçiliği Kurumu'na mahalli idareler ile ilgili yapılan başvuruların sayısı ve toplam başvuru içinde mahalli idareler ile ilgili yapılan başvuruların oranları hakkında şu sonuçlara ulaşılmıştır:

- 2013 yilında mahalli idareleri konu alan 455 başvurunun var olduğu görülmektedir. Bu başvurular toplam başvuruların \%6'sını oluşturmaktadır.

- 2014 yilında raporlar detaylandırılmıştır ve mahalli idareler ile birlikte idare bazında istatistiklere de yer verilmeye başlanmıştır. 2014 yllında mahalli idareleri konu alan başvuru sayısı bir önceki yıla göre azalmış ve 343 başvuru alınmıştır. Başvuru sayısı azalmış olmasına rağmen mahalli idareleri konu alan başvuruların toplam başvuru içerisindeki oranı artmıştır. $\mathrm{Bu}$ başvurular toplam başvuruların \%6,1'ini oluşturmaktadır. Raporda, başvuruların idare temelinde istatistiklerine de yer verilmiştir. Bu istatistikler incelendiğinde, mahalli idareler ile ilgili 511 başvurunun var olduğu ve bu başvuruların toplam başvuru sayısının \%9,6'sını oluşturduğu 
görülmektedir. $\mathrm{Bu}$ oran ile mahalli idareler toplam başvuruların idarelere göre dağılımında ilk sırayı almıştır.

- 2015 yılında ise mahalli idarelerce yürütülen hizmetler ile ilgili toplam 329 başvuru alınmıştır. Bu sayı toplam başvuruların \%5,43'ünü oluşturmaktadır. Şikâyet edilen idareler bazında dağılım incelendiğinde mahalli idareler ile ilgili olarak 506 başvurunun var olduğu ve bu sayının toplam başvuruların \%8,36’sını oluşturduğu görülmektedir.

2016 yılından itibaren ise yıllık raporlar içerisinde şikayetlerin alt başlıkları verilmeye başlanmıştır. Mahalli idareler ile ilgili Kamu Denetçiliği Kurumu’na 2016-2018 yılları arasında başvurusu yapılan şikayetlerin alt başlıkları Tablo 1'de yer almaktadır.

\section{Tablo 1. Kamu Denetçiliği Raporlarında Belirtilen Mahalli İdareler ile İlgili Şikâyetler}

\begin{tabular}{|l|r|r|r|}
\hline Hizmetler & \multicolumn{1}{|c|}{$\mathbf{2 0 1 6}$} & \multicolumn{1}{c|}{$\mathbf{2 0 1 7}$} & \multicolumn{1}{c|}{$\mathbf{2 0 1 8}$} \\
\hline Alt yapı hizmetleri & 23 & 173 & 120 \\
\hline Cenaze ve defin hizmetleri & 1 & 5 & 1 \\
\hline Çevre düzenleme & 8 & 11 & 42 \\
\hline Doğalgaz & 2 & 1 & 2 \\
\hline İmar ve bayındırlık işlem ve uygulamaları & 91 & 150 & 119 \\
\hline Kentsel dönüşüm ve konut üretimi ve satış & 4 & 19 & 19 \\
\hline Diğer konular & 98 & 164 & 213 \\
\hline Mali hizmetler & 5 & 57 & 59 \\
\hline Otopark Hizmetleri & 5 & 12 & 15 \\
\hline Ruhsat iş ve işlemleri & 40 & 109 & 143 \\
\hline Su & 25 & 82 & 233 \\
\hline Toplu taşıma hizmetleri & 50 & 91 & 107 \\
\hline Zabıta hizmetleri & 16 & 35 & 37 \\
\hline Katı atık yönetimi & 0 & 16 & 9 \\
\hline Evlendirme & 0 & 2 & 1 \\
\hline İtfaiye hizmetleri & 0 & 0 & 2 \\
\hline Toplam & 368 & 927 & 1122 \\
\hline
\end{tabular}

Tablo 1'de yer alan Kamu Denetçiliği Kurumu'na 2016-2018 yılları arasında başvurusu yapılan Mahalli idareler ile ilgili şikâyetlerin alt başlıkları incelendiğinde şu sonuçlara ulaşılmıştır:

- 2016 yılında mahalli idareler istatistiğinde başvuru sayısı 368 olarak gerçekleşmiştir. Bu sayı toplam başvuruların \%6,7'sini oluşturmaktadır. Şikâyet edilen idareler bazında dağılım incelendiğinde mahalli idareler ile ilgili olarak 558 başvurunun alındığı ve bu başvuruların sayısının toplam başvuru sayısı içerisinde \%10,11'lik kısmı oluşturduğu görülmektedir. En fazla şikâyet edilen idareler sıralamasında 2016 yılında ilk sırayı mahalli idareler almıştır.

- 2017 yılında mahalli idareler ile ilgili 927 başvuru alınmıştır. Bu rakam toplam başvuruların \%5,41'ini oluşturmaktadır. İdare temelinde değerlendirildiğinde toplam başvuruların \%8,31'i mahalli idareler ile ilgilidir. Bu oranın karşılığı 1424 başvurudur. Mahalli idarelere ait başvurular toplam başvurular içerisinde 3. sıradadır. 
- 2018 yılında mahalli idareler ile ilgili başvurular artış göstermiş ve 1122 başvuru alınmıştır. Bu başvurular toplam başvuru sayısının \%6,38'ini karşılamaktadır. İdareler temelinde verilen istatistikler incelendiğinde bu rakamın 1851'e ulaştığı ve toplam başvuru sayısının \%10'una denk geldiği görülmektedir. İdare temelli sıralamada mahalli idareler ile ilgili başvurular ilk sırada yer almıştır.

- Genel olarak daha fazla şikâyete konu olan hizmetlerin su, ruhsat iş ve işlemleri, altyapı hizmetleri, imar ve bayındırlık işlem ve uygulamaları, toplu taşıma hizmetleri gibi alanlar olduğu görülmektedir.

- Genel olarak daha az şikâyete konu olan hizmetlerin ise itfaiye hizmetleri, evlendirme, cenaze ve defin hizmetleri ile doğalgaz hizmetleri gibi alanlar olduğu görülmektedir.

Kamu denetçiliğinin yıllık raporlarında yer alan bu rakamlar değerlendirildiğinde mahalli idarelerin yürüttüğü hizmetlere ilişkin alınan şikâyetlerin yıllık olarak artış gösterdiği görülmektedir. Şikâyet edilen idareler temelinde yapılan değerlendirmelerde ise mahalli idarelerin toplam şikâyetlerin yaklaşık \%8 ile \%10'unu oluşturduğu ve şikâyet sıralamasında bazı yıllarda ilk sırayı aldığı ve genel olarak ilk üç idare içerisinde yer aldığı söylenebilir. Bu değerlendirmeler mahalli idarelerin kamu denetçiliği için önemli bir meşguliyet alanı olduğunun göstergesidir.

\section{Sonuç ve Öneriler}

İdarenin keyfi eylemlerine karşı vatandaşların korunması, idarenin devamlılığının sağlanması, meydana gelebilecek olumsuzlukların daha önceden tespit edilerek önlenmesi ya da olumsuzlukların giderilmesi gibi amaçlarla yönetimlerin denetlenmesi gerekmektedir. $\mathrm{Bu}$ gereksinimden hareketle farklı ülkelerde yönetimlerce çeşitli denetim mekanizmaları ve türleri geliştirilmiştir. Söz konusu denetim türlerinden biri de kamu denetçiliği olarak bilinen ombudsmanlık denetimidir.

Osmanlı Dönemi yönetim sisteminde varlığı bilinen ancak ombudsmanlık adıla ilk kez İsveç’te uygulanmaya başlayan kamu denetçiliği sistemi, Türkiye'de bu sistem çerçevesinde 2012 yılında 6328 sayılı “Kamu Denetçiliği Kurumu Kanunu” ile kurulmuş ve 1982 Anayasası'nın 74. maddesiyle anayasal bir kurum haline getirilmiştir. Kamu Denetçiliği Kurumu, idarenin işleyişi ve her türlü eylem, işlem, tutum ve davranışını gelen şikâyetler üzerine incelemekle görevli olan ve bu incelemeler sonucunda idareye öneriler sunan bir kurumdur.

Yerel yönetimler, kamu yönetimi teşkilatı içerisinde vatandaşların mahalli müşterek nitelikteki ihtiyaçlarını gidermek amacıyla kurulan yapılardır. Yerindelik ilkesi doğrultusunda hizmet sunumunu gerçekleștirmeleri, yerel yönetimlere vatandaşa en yakın idari birimler olma özelliği kazandırmaktadır. Bununla birlikte yerel yönetimlerin birer demokrasi okulu olarak görülmesi, onlara demokrasinin güçlü kılınması ve yerleşmesi için çeşitli roller verilmesini de beraberinde getirmektedir. Bu özellik ve verilen roller yerel yönetimlerin vatandaş ile olan ilişkisini önemli kılmaktadır. Çünkü yerel yönetimlerde demokrasinin istenilen düzeyde yerleşmesi ve güçlü kılınması için vatandaşın yönetime katılması ve yönetimin etkin bir denetim mekanizmasıyla denetlenmesi gerekmektedir. Dolayısıyla güçlü bir demokratik yapının varlığı için yerel yönetimler ile ilgili dile getirilen şikâyetlerin dikkate alınması ve gerekli incelemelerin yapılarak doğru sonuçlara ulaşılması gerekmektedir. 
Kamu Denetçiliği Kurumu'nu alan ayrımı yapmaksızın tüm başvuruları almakta ve değerlendirme yapmaktadır. Alan ayrımı yapılmaması, kuruma yapılan yerel yönetimlerle ile ilgili başvurulara gerekli önemi göstermekte zorluk yaşayabileceğini düşündürmektedir. 2018 yılında 21.647 başvuru alınmış ve bunların 17.615 tanesi sonuçlandırılabilmiştir. Alınan başvurular içerisinde her yıl için ortalama \%8 ile \%10 arasında başvuruyu oluşturan yerel yönetimler ile ilgili şikâyetlerin yerel kamu denetçiliği kurumunun oluşturulup faaliyete geçirilmesi ile bu kuruma aktarılması, kamu denetçiliğinin yükünü hafifletebilecek ve kurum içinde daha sağlıklı işleyen bir mekanizmanın oluşmasına olanak sağlayabilecektir. Bunun yanı sıra yerel yönetimler ile ilgili şikâyetlerin daha detaylı incelenmesi ve daha sağlıklı sonuçların üretilebilmesi sağlanabilecektir.

Hak arama kültürünün kazandırılmasını amaçlayan kamu denetçiliği kurumuna vatandaşların daha kolay ulaşmasının sağlanması konusunda yine yerel kamu denetçiliğinin olumlu etkilerinin olacağı düşünülmektedir. Kamu denetçiliği kurumuna yapılan başvurularda genellikle e-devlet üzerinden başvuru alınmaktadır. Ülkemizde e-devlet kullanan kişi sayısının 19 milyon olduğu düşünüldüğünde, e-devlet başvurularının çok fazla tercih edilmediği söylenebilir. Kamu denetçiliği kurumunun aldığı başvurularda elden dilekçe, faks, posta ve eposta gibi başvuru şekillerinin olduğu görülmektedir. Bu nedenlerle yerel kamu denetçilerinin varlığı yerel anlamda vatandaşların kendisine daha yakın olan bir denetçi kuruluşa başvurmasını daha mümkün ve kolay kılacaktır.

Vatandaşın mahalli müşterek nitelikteki ihtiyaçlarını gidermeye çalışan yerel yönetimler vatandaşlara en yakın birimler olarak görülmektedir. Oluşturulacak yerel yönetimler kamu denetçiliği ile vatandaşa en yakın birimler olan yerel yönetimler hakkında dile getirilen şikâyetlerin, yine vatandaşa en yakın bir denetim mekanizması ile çözülmesine olanak sağlanacaktır. Diğer taraftan vatandaşların gereksiz bürokratik yoğunluğu yaşamamış olmaları ve sorunlarının kısa zamanda çözülmüş olabilmesi, onların yönetime katılımlarının sağlanması açısından da önem arz etmektedir. Bununla birlikte yerel yönetimler, yapılan şikâyetler üzerine sorunların yerinde tespit edilip çözülmesiyle daha etkin ve verimli bir hizmet sunumu arayışı içinde olabilecektir.

\section{Kaynakça}

Akıncı, M. (1999). Bağımsız İdari Otoriteler ve Ombudsman, İstanbul: Beta Yayınevi.

Ataman, T. (1997). Ombudsman ve Temiz Toplum. Yeni Türkiye Dergisi, 14(1), 783- 802.

Avşar, Z. (2012). Ombudsman İyi Yönetilen Türkiye İçin Kamu Hakemi. İstanbul: Hayat.

Eryılmaz, B. (2011). Kamu Yönetimi/Düşünceler/Yapılar/Foksiyonlar/Politikalar (4.baskı). Ankara: Okutman.

Fendoğlu, H.T. (2010). Kamu Denetçiliği (Ombudsmanlık), http://hasantahsinfendoglu.com/dokumanlar/insan_haklari/KAMU_DENETCILIGI_O MBDUSMANLIK_.pdf, Erişim Tarihi: 20.04.2019. 
Gökçe, A.F. (2013). Kamu Denetçiliği Sistemi Kapsamında Mahalli İdarelerde Ombudsman Denetimi, KAYSEM-8 Kuramdan Uygulamaya Yerel Yönetimler ve Kentsel Politikalar Bildiri Kitab1, 11-12 Mayıs 2013, Hatay.

Gregory, R. (1995). The Ombudsman in Perspective, (Ed.) Roy Gregory - Philip Giddings Victor Moore - Jane Pearson, Practice and Prospects of the Ombudsmen in the United Kingdom, Lampeter, The Edwin Mellen Press, 1-42.

Köksal, M. (2007), Ombudsman (Kamu Hakemi), Ankara: Işık Eğitim Kültür Hizmetleri.

Küçüközyiğit, H. G. (2006), Ombudsmanlık Kurumu-Hukuksal ve Siyasal Bir İnceleme, Uluslararası Hukuk ve Politika Dergisi, 2(5), 90-111.

Nohutçu, A. (2007). Kamu Yönetimi, Ankara: Savaş.

Özden, K. (2004). Yerel Yönetimler Ombudsmanı, Yerel Yönetimler Kongresi, 3-4 Aralık 2004, Biga/Çanakkale.

Özden, K. (2010). Ombudsman ve Türkiye'deki Tartışmalar. Ankara: Seçkin Yayıncılık.

Özer, M.A. ve Önen S.M. (2016). 200 Soruda Yönetim Kamu Yönetimi, Ankara: Gazi Kitabevi.

Parlak, B. ve Doğan K.C. (2015). Türkiye'de Ombudsmanın Uygulanabilirlik Analizi: Ampirik Bir Çalışma, Turkish Studies, 10(10), 749-770.

Sanal, R. (2002). Türkiye'de Yönetsel Denetim ve Devlet Denetleme Kurumu, Ankara: TODAİE.

Seneviratne, M. (1994). Ombudsmen in the Public Sector, Law and Political Change. UK: Open University Press.

Şencan, H. (2011). Bazı Ülkelerde Ombudsmanlık Kurumu, Türkiye Büyük Millet Meclisi Araştırma Merkezi, Ocak, 8-40.

Şengül, R. (2013). Kamu Yönetimi ile Birey İlişkilerinin Dönüşümüne Ombudsman Kurumunun Etkisi, Süleyman Demirel Üniversitesi İktisadi ve İdari Bilimler Fakültesi Dergisi, 18(3), 71-88.

Temizel, Z. (1997). Yurttaşın Yönetime Karşı Korunmasında Bă̆ımsız Bir Denetim Organı Ombusman. İstanbul: IULA-EMME.

Tortop, N. (1998). Ombudsman Sistemi ve Çeşitli Ülkelerde Uygulanması, Amme İdaresi Dergisi, 31(1), 3-11.

Tortop, N. İsbir, E.G. Aykaç, B. (1993). Yönetim Bilimi Ankara: Yarg1.

Uler, Y. (2012). Ombudsman (Kamu Denetçisi), (Editörler), Burhan Aykaç, Şenl Durgun ve Hüseyin Yayman, Türkiye'de Kamu Yönetimi, Ankara: Nobel Akademik.

Ünal, F. (2008). Türkiye'de Yerel Yönetimlerin Denetimi ve Yerel Yönetim Ombudsmanı, (Yayımlanmamış Doktora Tezi), Gazi Üniversitesi Sosyal Bilimler Enstitüsü, Ankara. 